\title{
ist \\ Louis-Bernard Guyton de Morveau e a revolução química das Luzes
}

Ronei Clécio Mogeldin

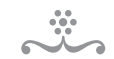

RESUMO

O objetivo deste artigo é investigar a concepção enciclopédica de revolução científica posta em prática pelo químico francês L. - B. Guyton de Morveau (1737-1816). Deslocando a análise do conhecimento químico das Luzes do programa traçado por Lavoisier (174:3-1794), sugerimos uma concepção revolucionária republicana, proclamada como resultado do esforço de uma coletividade. Daremos destaque a três abordagens revolucionárias de Guyton de Morveau no âmbito da química. A primeira foi sua atuação no ensino dessa ciência, cuja pedagogia e métodos de ensino foram fundamentais para sua imersão social. Além disso, entre 1770 e 1790 , Guyton de Morveau teve desempenhos decisivos no seio da empresa enciclopédica e no seio da escola química francesa.

Palavras-Ghave • Revolução química. Guyton de Morveau. Enciclopédia metódica.

Afinidades químicas.

\section{INTRODUÇÃO}

A revolução química é um rio. Aimagem heraclitiana proposta por alguns comentadores para definir a diversidade do pensamento de Denis Diderot parece-nos também adequada para abarcar a pluralidade de interpretações da chamada "revolução química", ocorrida nas últimas décadas do século xviıI (cf. Fontenay, 1982). Além de federar as conclusões dos historiadores da química, essa associação metafórica serve-nos também para indicar que ambos os rios nasceram no mesmo contexto histórico, uma vez que não podemos esquecer que foi no século das Luzes que a expressão "revolução científica" ganhou contornos modernos (cf. Cohen, 2001 [1985]).

O emprego da expressão "revolução química" quase sempre faz referência a Antoine de Lavoisier, personagem tradicionalmente considerado por historiadores e filósofos da ciência como o grande artífice de uma química moderna. Embora as duas últimas gerações de historiadores da química tenham dissipado a ideia clássica de um pai fundador, Lavoisier resta reconhecido como alguém que aplicou seu gênio revolucionário nas diversas atividades de que se ocupou (cf. Actes des colloques, 1995). 
Em relação à química, historiadores e epistemólogos, mesmo divergindo quanto à abrangência, aos fundamentos epistêmicos, ou à coerência do sistema antiflogístico, parecem concordar que os trabalhos de Lavoisier em química foram revolucionários (cf. Guerlac, 1961; Donovan, 1993; Bensaude-Vincent, 1993; Beretta, 1993).

Identificar Lavoisier e seu sistema químico como responsáveis por uma grande revolução científica serviu a muitos interesses, tanto historiográficos quanto epistemológicos. Nas histórias clássicas da química, o mito de um fundador ajudava sobremaneira na demarcação entre um período pré-científico e outro no qual, enfim, a química tornava-se uma ciência positiva. A química lavoisieriana também serviu como ponto de apoio para vários modelos epistemológicos, particularmente aqueles que incorporavam a história da ciência em suas argumentações. É bem conhecida a importância dada por Thomas Kuhn à revolução liderada por Lavoisier na construção de seu modelo explicativo para o progresso científico através de saltos revolucionários (cf. Kuhn, 1975 [1962]).

Comentadores da obra de Kuhn reforçaram a convicção de que, de fato, a revolução lavoisieriana era exemplar na explicação do significado de uma ruptura paradigmática, pois esclarecia as principais noções envolvidas nesse tipo de processo (anomalias, período de crise, nova teoria explicativa, resistência comunitária, nova linguagem, incomensurabilidade ontológica e linguística, e conversões) (cf. Hoyningen-Huene, 2008). Outros, ainda, viram a possibilidade de desenvolver modelos derivados da ciência computacional para explicar como as transformações conceituais ocorriam utilizando a trajetória revolucionária de Lavoisier como caso exemplar (cf. Thagard, 2007 [1990]). Se na historiografia tradicional a nova química representava uma revolução empírica (a química tornava-se uma ciência), nas interpretações histórico-epistemológicas como essa dos kunhianos, mas também naquelas de Hélène Metzger (1932), de Gaston Bachelard (1973 [1932]), ou de François Dagognet (2002 [1969]), ela exemplifica uma revolução ontológico-epistêmica.

Em sua reconstrução do contexto histórico e da historiografia do conceito de "revolução química”, Bernadette Bensaude-Vincent aponta para os limites dessas interpretações. Para Bensaude-Vincent, com seu método (experimental, quantitativo, que tem precisão instrumental), seu estilo (de escrita, de vida social e acadêmica), sua escola e com os meios institucionais de que dispunha, Lavoisier realizou, de fato, uma revolução. Mais do que isso, pois sua revolução consistia em uma novidade na própria noção que se tinha do termo. Para começar, não se tratava de uma revolução científica tardia ocorrida na química. Na verdade, segundo Bensaude-Vincent, ela consiste no melhor exemplo do significado moderno da expressão, como ruptura que fazia tábula rasa do passado e inaugurava uma nova temporalidade. Porém, essa revolução não marca a origem da química moderna, nem tampouco cumpre os quesitos demandados por 
modelos epistemológicos estranhos à própria problemática enfrentada pelos químicos da época e do lugar social de sua ciência. A revolução realizada por Lavoisier dá sentido ao conceito de revolução como ruptura, mas não exemplifica nenhuma teoria epistemológica particular. Devido a circunstâncias locais precisas e ao proteísmo das interpretações históricas, a revolução que Lavoisier efetivamente realizou foi mais de caráter historiográfico do que de natureza paradigmática (cf. Bensaude-Vincent, 1993, p. 4,23).

Não contestaremos esse caráter revolucionário da obra de Lavoisier. Gostaríamos de precisar, todavia, que o conceito de "revolução científica", desenvolvido por ele, não pode ser utilizado nem para analisar o pensamento químico do século xvıı,, nem como o único significado conceitual de "fazer-se uma revolução na ciência". Da polissemia do termo, reteremos a distinção feita por Bensaude-Vincent entre a perspectiva revolucionária defendida na Enciclopédia de Diderot e d'Alembert e aquela adotada por Lavoisier. Enquanto na Enciclopédia, particularmente no artigo "Chymie" escrito pelo médico-químico Gabriel-François Venel (1967 [1753]), o termo "revolução" era empregado como o intuito de proclamar uma autonomia epistêmica e para reivindicar um lugar de destaque para a ciência química na sociedade, para Lavoisier o termo servia para delimitar um espaço preciso, para indicar uma ruptura com o passado a fim de demarcar um antes e um depois, ou seja, para indicar o início de uma nova história. A química das Luzes foi, assim, o teatro para duas concepções distintas de progresso científico e de trabalho comunitário. No ideal enciclopédico, uma revolução na química seria obra coletiva, enquanto que para Lavoisier ela significava a aceitação de seu sistema (cf. Bensaude-Vincent, 1993).

A partir dessa distinção, reservaremos a expressão "revolução química" para identificar o conjunto de esforços realizados pela "república dos químicos" da segunda metade do século das Luzes para fazer progredir sua ciência, enquanto que por revolução lavoisieriana entenderemos as contribuições do próprio Lavoisier. ${ }^{1}$ Portanto, ao utilizarmos a imagem fluvial para federarmos as múltiplas interpretações de "revolução química", gostaríamos de indicar não apenas a complexidade desse evento histórico e de suas possíveis leituras, mas, sobretudo, que nesse grande rio conceitual deságuam vários afluentes. Os historiadores da química têm revelado o quanto alguns deles contribuíram na construção de uma identidade epistêmica para o pensamento químico daquele período. Joseph Black, Joseph Priestley, Pierre-Joseph Macquer, Torbern Bergman, Richard Kirwan, Louis-Bernard Guyton de Morveau, para citar apenas os mais conhecidos, exemplificam alguns desses poderosos afluentes conceituais.

1 A expressão “república dos químicos” não sugere a existência no século xvıı de uma disciplina ou comunidade bem delimitada. Ela procura simplesmente aproximar-se da noção que se tem de "república das letras”. Seriam cidadãos dessa república todos aqueles que se declarassem químicos e contribuíssem com trabalhos sobre questões relativas às transformações materiais obtidas em laboratório (cf. Bots \& Waquet, 1997). 
Essas observações justificam e, ao mesmo tempo, limitam o uso de nossa metáfora fluvial. Justificam no sentido que demonstram que a revolução química não pode ser identificada exclusivamente a Lavoisier, mas, ampliando as margens conceituais, limitam sua precisão. Enquanto são bem conhecidos os passos do "programa revolucionário" de Lavoisier, sua história e sua historiografia, as forças que movem e alimentam um processo revolucionário estendido restam bem menos evidentes (cf. McEvoy, 2010).

Assim, o objetivo deste artigo será o de investigar a concepção enciclopédica de revolução científica posta em prática pelo químico francês Guyton de Morveau. Além de descolar a análise do conhecimento químico das Luzes do programa traçado por Lavoisier, sugerimos uma concepção revolucionária republicana, no sentido de ser resultado de um esforço de uma coletividade. Nessa concepção, ser revolucionário era agir na promoção das novas ideias científicas e filosóficas, participar da "efervescência geral" da sociedade e, seguindo a instrução de Voltaire, o grande patrono dessa revolução, difundir e tornar disponível ao público as novas luzes do esclarecimento (cf. Reichardt, 2007).

Daremos destaque a três contribuições revolucionárias de Guyton de Morveau no âmbito da química. A primeira foi sua atuação no ensino dessa ciência, cuja pedagogia e didatização eram fundamentais para sua imersão social (cf. Hannaway, 1975). Ensinar e divulgar a ciência química fazia Guyton de Morveau participar concretamente da revolução pedagógica proclamada pelos filósofos das Luzes. Além de inovar na organização pedagógica do conhecimento químico, Guyton de Morveau participou também de dois outros momentos revolucionários ocorridos nos anos 1770-1790, o primeiro no seio da empresa enciclopédica e o segundo no seio da escola química francesa.

\section{A REVOLUÇÃo PEDAGóGica}

Os debates pedagógicos ao longo do século xvıII foram profundamente influenciados pela filosofia de John Locke, que reabilitava a percepção, tornando-a condição de todas as nossas ideias. Na França, Étienne Bonnot de Condillac foi o principal articulador de uma aproximação teórica entre o empirismo lockeano e o intelectualismo cartesiano, que resultou em um sistema filosófico que tinha na sensação o princípio para qualquer investigação acerca do entendimento humano (cf. Quarfood, 2002).

Guyton de Morveau concordava com as linhas gerais desses projetos filosóficos, mas considerava que a defesa de uma nova educação era de pouca valia, se não viesse acompanhada de uma verdadeira reestruturação dos estabelecimentos de ensino e de seus procedimentos. E, para isso, não era suficiente apontar os defeitos do método 
regular, a importância das artes e das ciências para a sociedade, ou ainda a urgência de uma legislação nacional e centralizada. Era necessário passar a um segundo nível de ação, era preciso pensar a reforma em seus detalhes, caso contrário, os anseios de reforma não passariam de discursos de intenções, sem realizações efetivas. Em sua Dissertação sobre a educação pública, escrita com o objetivo de propor um novo programa pedagógico para os colégios franceses após a expulsão dos Jesuítas (1762), Guyton de Morveau descrevia o papel desses estabelecimentos como elo entre a esfera privada e o mundo público e abordava, sucessivamente, os costumes, a idade de ingresso, o ensino, a escolha dos professores, o método, e concluía apresentando uma reestruturação administrativa (cf. Guyton de Morveau, 1764).

A qualidade dessa dissertação rendeu a Guyton de Morveau sua entrada na Academia de Ciências, Artes e Belas Letras de Dijon, instituição que marcará profundamente sua trajetória intelectual e política (cf. Rorgue, 2006). Se essa reflexão pedagógica possibilitou-lhe entrar no mundo acadêmico, seu Digressões acadêmicas abriu-lhe as portas da república dos químicos. Com esta obra, Guyton de Morveau passou a ser reconhecido como um químico de grande talento, sendo aclamado pelo meio científico (cf. Guyton de Morveau, 1772). Embora discordasse da explicação dada ao fenômeno, Lavoisier considerou que esse trabalho era o primeiro a demonstrar experimentalmente o aumento da massa dos metais após sofrerem calcinação (cf. Lavoisier, 1801 $[1774])$.

A partir de $177^{6}$, Guyton de Morveau assumiu a responsabilidade de conduzir o curso de química na Academia de Dijon. A primeira originalidade de seu curso era a de que os alunos não precisariam transcrever a apresentação oral, como era costume, mas dispunham de um manual didático. Mesmo que já existissem diversos manuais de ensino de química, o Elementos de química teórica e prática foi o primeiro a ser organizado para um curso específico (Guyton de Morveau, 1777/ $7^{8}$ ). Tanto o manual, que foi logo traduzido para o alemão e para o espanhol, quanto o curso obtiveram um enorme sucesso. Anualmente, durante três meses (fev./mar./abr.), alunos de toda a Europa vinham a Dijon frequentar o curso no laboratório da Academia (cf. Mocellin, 2010, p. 180).

Acompanhar esses cursos era a garantia de estar atualizado sobre as últimas novidades teóricas e experimentais de uma ciência em rápido desenvolvimento. Estruturado em torno de um "programa newtoniano", todas as explicações teóricas eram submetidas a uma demonstração experimental e os resultados agrupados em tabelas que sintetizavam um grande número de possibilidades de combinações químicas. Essas tabelas organizavam o conhecimento químico e funcionavam como instrumentos pedagógicos que facilitavam o aprendizado, privilegiando mais o entendimento que a memorização de possíveis comportamentos reativos (cf. Klein \& Lefèvre, 2007). 
A organização didática dos conteúdos trazia outra novidade. A maioria dos manuais e tratados de química publicados na França do século xvııI organizava suas lições seguindo a divisão dos três reinos - mineral, vegetal e animal (cf. Simon, 1999). O manual elaborado por Guyton de Morveau desconsiderava esta divisão clássica e organizava as operações químicas seguindo a teoria química das dissoluções. Convém lembrar que, para os químicos do século xviıI, o termo dissolução designava uma composição química e não uma simples divisão mecânica (cf. Macquer, 1766).² Através dessa operação, os corpos eram postos em contato, ou melhor, em relação, possibilitando interações, que poderiam resultar em novas composições. A dissolução representava a operação química e permitia relacionar aquilo que os químicos consideravam essencial a sua ciência, ou seja, a composição e as forças naturais que a possibilitavam (cf. Metzger, 1974 [193o], p. 280).

O principal objetivo do curso era formar pessoas interessadas em aplicar a química em alguma atividade produtiva. Como Dijon não dispunha de uma faculdade de medicina, o curso também servia à formação de farmacêuticos e o laboratório dirigido por Guyton de Morveau também funcionava como centro de análises técnicas demandadas pelo Estado da Borgonha ou por empreendedores particulares da província (cf. Baudot, 2002 [1905]). Mas, além desse lado prático, organizou-se em torno do curso um ambiente de intensa atividade social. Uma das mais importantes foi o grupo de tradução organizado por Guyton de Morveau e Claudine Picardet, que traduziu para o francês obras de químicos suecos, ingleses, alemães e italianos, contribuindo assim para disseminar as Luzes vindas do estrangeiro (cf. Bret, 2008a). Na esfera institucional, a guinada científica que Guyton de Morveau e Hugues Maret, seu grande apoiador, imprimiram nos anos 1780 inverteu o papel social tradicionalmente desempenhado pela Academia. De um espaço eminentemente literário e com critérios de admissão pouco claros, durante a direção de Guyton de Morveau, a Academia tornouse um centro de produção e de divulgação do conhecimento científico, além de referência para outras academias europeias (cf. Lamarre, 1999).

O projeto teórico-pedagógico de Guyton de Morveau era criar uma educação nacional e centralizada. Para o historiador da pedagogia Yves Lagrée, as reformas preconizadas em textos como a Dissertação de Guyton de Morveau testemunham a origem de uma corrente pedagógica que se preparava para ocupar as instituições de ensino assim que a política permitisse. A revolução de 1789 possibilitará uma nova ocasião. Social e política, a revolução francesa será também pedagógica (cf. Lagrée, 1985). Enfim, Guyton

2 Segundo Macquer, "A dissolução consiste na união das partes integrantes de um corpo com as partes integrantes de um corpo de uma natureza diferente; \& como dessa união sempre resulta um novo composto, vê-se disso que a dissolução não é outra coisa que o ato mesmo da combinação" (Macquer, 1766, v. 1, p. 351). 
de Morveau era advogado-geral no Parlamento da Borgonha, quando escreveu sua Dissertação e, segundo o historiador Roger Chartier, as propostas dos parlamentares, sintetizadas em 1768 na dissertação redigida pelo presidente do Parlamento de Paris, Rolland d'Erceville, não eram tão diferentes daquelas postas em prática nas futuras escolas revolucionárias (cf. Chartier, 1976).

Mas foi através do ensino de química que Guyton de Morveau aplicou seus conceitos pedagógicos, tanto na organização didática quanto institucional. Mais do que proclamar uma revolução pedagógica, Guyton de Morveau a realizou de forma concreta, localizada. Além de pedagógica, essa revolução também foi institucional, pois fez da Academia de Dijon um lugar de articulação conceitual da "república das ciências" no nível nacional e internacional (cf. Bret, 2008b).

A Revolução francesa oferecerá a Guyton de Morveau a possibilidade de aplicar suas ideias pedagógicas e de ensino de química em uma escala nacional. Um dos articuladores do grupo de cientistas envolvidos em projetos militares destinados a "salvar a República”, Guyton de Morveau também será um dos organizadores dos cursos revolucionários e, mais importante, um dos fundadores da grande instituição pedagógica criada pela Revolução, a Escola Politécnica (cf. Belhoste, 1994).

\section{A REVOLUÇÃo IDENTITÁRIA}

A química ocupava um lugar central na cultura do século das Luzes. Útil tanto aos médicos, quanto aos farmacêuticos, aos metalurgistas, aos tintureiros, aos exploradores de minas e de outras riquezas nacionais, a química respondia aos ideais que guiavam o desenvolvimento da ciência. Na França, a importância institucional pode ser medida pela criação de uma cátedra de química pela Academia Real de Ciências de Paris, em 1699, e de cursos de química (públicos e privados) em várias cidades do país. Na Academia Real, mais relevante do que a criação, foi propriamente o desenvolvimento de programas de investigação de longa duração, particularmente aqueles sobre a análise química dos vegetais (destilação/extração por solventes) e da química dos sais, que serão os principais eixos da pesquisa da química francesa durante o século xviıI (cf. Holmes, 1971, 1989).

Assim, o reconhecimento social e institucional da química já era uma realidade na metade do século, quando a Enciclopédia ou Dicionário racional das ciências, das artes e dos ofícios de Denis Diderot e Jean d'Alembert (1967 [1751- 72$]$ ) começou a ser redigida. Se o artigo "Chymie" dá a impressão de uma ciência que continuava a ser desprezada e sem o respeito que merecia, sobretudo da parte dos doutores da universidade, e à espera de um novo Paracelso, isso resulta mais de seu caráter publicitário do que do re- 
trato teórico-experimental da química de sua época. Recentemente, um novo olhar sobre o lugar da química na Enciclopédia revelou o quanto ela era importante na sustentação da própria filosofia do projeto e aponta para o fato de que, se quisermos conhecer o sistema químico enciclopédico, não podemos nos limitar ao famoso artigo (cf. Lehman \& Pépin, 2009).

Queremos destacar aqui dois aspectos da apresentação da química na Enciclopédia. O primeiro diz respeito ao caráter epistemológico do discurso de Venel no artigo "Chymie". Além de refutar o reducionismo da química à física (no sentido de uma física geral) e de delimitar a esfera da ação química e da ação física, Venel advogava que a originalidade da ciência química estava no caráter indissociável entre a teoria e a prática, e no próprio químico, em seu corpo, em seus hábitos e na sua experiência. Ou seja, ao menos no discurso, a química opunha-se ao mecanismo fisicalista e reivindicava uma originalidade cultural. O segundo diz respeito, justamente, ao conceito que nomeará essa "esfera de ação química”.

Ao opor a química à física, Venel defendia a possibilidade de uma ciência que obedecia aos resultados quantitativos, mas não os considerava prioritários em relação aos aspectos qualitativos da matéria. Em química, as medidas rigorosas seriam inseparáveis do "bom senso" do químico, de sua experiência prática, de seu "golpe de vista" preciso. O objetivo de Venel era apresentar a química como racionalmente qualitativa, que tornava inseparáveis a ciência das técnicas operacionais. Ao valorizar o trabalho e os hábitos dos químicos, Venel reivindicava uma singularidade para a química junto aos meios intelectuais partindo de uma análise do comportamento de seus praticantes, deslocando a discussão sobre como tornar um saber eminentemente empírico em uma verdadeira ciência. O fundamento epistêmico das práticas químicas seria conhecido na medida em que compreendêssemos as operações envolvidas, os princípios e os instrumentos que estavam agindo (cf. Venel, 1967 [1753]).

Na defesa dessa identidade epistêmica, Venel fazia dos químicos um "povo distinto", com uma cultura particular. Nessa campanha publicitária de promoção da química, o que contava não era a real relação entre a física geral e a química (física particular), mas mostrar que a química era independente, tanto ontológica quanto epistemologicamente. Aliás, essa característica da química motivou a construção de uma filosofia experimental que tinha por objetivo oferecer explicações às operações materiais (da natureza ou da arte) a partir delas mesmas, e não de princípios a priori externos. Dado que a epistêmê química era inseparável das operações químicas, filósofos como, por exemplo, Diderot e o Barão d'Holbach tomaram a química como modelo para uma filosofia materialista que rompia com as distinções clássicas, tais como corpo/espírito ou sentimento/julgamento, mas também com certas divisões sociais, tais como ciência nobre/ciência vulgar e ciência reflexiva/saber empírico (cf. Pépin, 2010). 
Ao contrário do que comumente se imagina, o "flogístico" não era o conceito central da química do século xviı. Na Enciclopédia, o artigo "Phlogistique" reenvia o leitor ao artigo "Feu" que, por sua vez, afirma que uma explicação mais adequada seria dada no artigo "Phlogistique" (Venel, 1967 [1756]). Finalmente, nenhuma definição precisa é oferecida. No artigo "Feu”, cuja "parte química" foi redigida por Venel, encontramos, todavia, uma definição geral do flogístico, que seguia a reorganização teórica realizada pela escola de Guillaume-François Rouelle, que fusionava a teoria dos elementos-princípios de Stahl com a teoria das dissoluções e dos instrumentos de Herman Boerhaave. Segundo Venel, o flogístico era o fogo-elemento, ou melhor, a parte do fogo fixada nos corpos, que tomava parte das operações químicas, sendo percebido pela cor, pelo odor ou pela inflamabilidade que sua presença podia causar (cf. Lehman, 2008).

Se retrospectivamente a história da química viu na teoria do flogístico aquilo que identificava uma química pré-lavoiseriana, isso resulta mais de uma reconstrução do passado em função das controvérsias que a historiografia elegeu como importantes do que a realidade conceitual da química ao longo do século xviı. Neste período, o flogístico era considerado um corpo químico como outro qualquer, presente na famosa Tabela de relações de Etienne-François Geoffroy, e que podia tomar parte daquilo que realmente caracterizava o território epistêmico da química das Luzes, ou seja, o flogístico, como outros princípios resultantes da análise química, entrava na composição dos mixtos (cf. Bensaude-Vincent, 2008).

Além de reivindicar uma cultura particular, o artigo "Chymie" esclarecia qual era a diferença irreconciliável entre as explicações químicas e físicas. Enquanto as forças químicas agiam nas partes constituintes dos corpos, as forças físicas atuavam entre suas partes integrantes. As partes constituintes mais simples obtidas por um processo de análise eram chamadas de elementos ou princípios e sua combinação produzia um corpo composto denominado mixis (mixte ou mixto, para diferenciar de misto, associado à ideia de mistura). Não apenas os elementos-princípio - ar, fogo, terra e água combinavam-se para formar mixtos, mas também corpos sabidamente compostos que comportavam-se como corpos simples (resultado analítico), como era o caso dos ácidos, dos álcalis ou dos metais. Enfim, indo além da publicidade pela dignidade da química, Venel identifica a química como sendo a ciência que operava sobre os mixtos, cujas partes eram heterogêneas, enquanto que a física se ocupava dos corpos como massas homogêneas ou agregados (cf. Venel, 1967 [1765]). Portanto, o conceito de mixis identificava uma esfera propriamente química de investigação.

Mas qual seria a natureza dessa força química que agia nos mixtos? Para responder a questão é necessário, antes, observar certa nuance entre a definição técnica de mixto (devido à Stahl e em oposição à noção aristotélica) e seu uso como um conceito químico identitário por Venel. Segundo a hierarquia da matéria definida por Stahl, um 
mixto seria o primeiro estágio de combinação de certos princípios. Porém, para Venel, o verdadeiro objeto de trabalho no cotidiano dos químicos eram os compostos (combinação de mixtos). Desta nuance quanto ao emprego do termo, temos que o papel do mixto na marcação de uma identidade para a química estava em sua característica operatória, e não como um suposto último estágio da materialidade. Quer dizer, os químicos não estavam interessados em uma teoria da matéria, mas sim na compreensão das transformações materiais. Esta característica determinava as condições para a formação de um novo mixto: dissolução, vizinhança, afinidade e proporção. Destas, a condição de afinidade é a que pode informar-nos sobre a natureza da ação propriamente química. Aqui, o termo afinidade designava a disposição de certas substâncias a unirem-se quimicamente a outras; essa força química não tinha antagonismo, ou seja, ela não evocava o conceito duplo de atração/reação de Newton. Trata-se de um conceito qualitativo que permitia a comparação e a classificação, como aquela oferecida pela Tabela de relações de Geoffroy (cf. Bensaude-Vincent, 2009).

$\mathrm{Na}$ Enciclopédia de Diderot e d'Alembert, a identidade da química era defendida a partir da originalidade da cultura dos membros da república dos químicos e do conceito operatório de “mixto". Contudo, os critérios de identificação adotados na Enciclopédia tornavam-se cada vez mais problemáticos à medida que novos trabalhos iam sendo publicados, e também devido ao progresso na organização e na comunicação entre os membros da república. Na verdade, a imagem militante de um "povo distinto", proposta por Venel, perdia o sentido na medida em que o rigor das medidas experimentais e o uso de uma linguagem quantitativa tornavam-se comuns entre os químicos dos anos 1770, sem que com isso a química perdesse sua identidade epistêmica.

Além disso, o conceito de afinidade para explicar a ação química não poderia limitar-se ao aspecto operatório e classificatório. Esse conceito estava cada vez mais associado com a noção de força, ou seja, avançava uma interpretação que integrava a afinidade que seria própria da esfera do mixto com o conceito geral de afinidade oferecido pelos newtonianos. Certamente, na Enciclopédia, Venel rejeitava a submissão da química à física newtoniana. Porém, nos artigos em que a defesa da identidade química não estava em jogo, Venel não propunha uma explicação para as afinidades químicas diferente daquela oferecida pelos químicos newtonianos (cf. Lehman, 2008, p. 453).

Portanto, a identidade da química projetada pela Enciclopédia não representava mais a química efetivamente praticada nos laboratórios. As imperfeições da grande Enciclopédia não se limitavam à química, de modo que mesmo antes de concluída a aventura enciclopédica (1751-1772), os editores já planejavam uma nova empresa editorial. No entanto, por não receber autorização do Estado, o novo editor, Charles Panckoucke, decidiu publicar em 1776/77 apenas uma série de Suplementos destinados a corrigir os equívocos de certos artigos (cf. Darton, 1996). 
Devido a sua saúde debilitada, Venel será obrigado a desfazer o acordo com Panckoucke para corrigir a parte química. O sucesso de seu Digressões e uma sólida amizade com Georges-Louis Leclerc, conde de Buffon, cujos trabalhos eram publicados por Panckoucke, fizeram com que Guyton de Morveau fosse escolhido para cumprir essa tarefa. Estendendo a colaboração, Guyton de Morveau foi nomeado responsável de uma nova empreitada enciclopédica dirigida por Panckoucke, profundamente diferente da antiga e que tinha por tarefa descrever com precisão o estágio de desenvolvimento do conhecimento químico da época (cf. Tucco-Chala, 1977).

O monumental Dicionário de química da Enciclopédia metódica (6 tomos até 1815) começou a ser redigido em 1782, e o primeiro tomo, publicado em duas partes, foi escrito por Guyton de Morveau (cf. Bret, 2006). A primeira parte foi publicada em 1786, pouco antes do encontro que selou seu acordo com Lavoisier sobre as afinidades envolvidas na combustão do fósforo e do enxofre, e a segunda parte em 1789, pouco tempo depois da formação da escola francesa de química (cf. Guyton de Morveau, Maret \& Duhamel, 1786/1789). Além de uma profunda reformulação teórica, Guyton de Morveau propunha uma mudança radical na identificação dos químicos e do papel da química na sociedade. Podemos dizer que, se fazer uma revolução científica em sentido enciclopédico era um processo de permanente reconstrução identitária forçado pelo próprio progresso da ciência, a organização didática e a química exposta por Guyton de Morveau caracterizam uma profunda revolução.

Para Guyton de Morveau, nem os químicos eram um “povo distinto”, nem a química era uma ciência cujos princípios teóricos eram alheios a uma física geral. Quer dizer, o discurso epistemológico não era mais o mesmo. Porém, como vimos acima, não podemos ficar limitados ao discurso publicitário de Venel no julgamento da rede conceitual que constitui a química do século das Luzes e da exposição do conhecimento químico pela Enciclopédia. Dizemos isso, porque queremos diferenciar nosso caminho de comparação entre as duas enciclopédias daquele seguido por Maurice Daumas, que centrou sua análise em uma interpretação um pouco caricatural dos trabalhos de Venel e de sua recusa em definir as afinidades químicas em termos newtonianos (cf. Daumas, 1951).

Dois artigos dos Suplementos marcam a diferença entre a nova e a antiga química enciclopédica. No artigo "Phlogistique", ausente na antiga Enciclopédia, Guyton de Morveau afirmava que "à medida que a química progride, os termos que lhe são próprios tornam-se comuns à física (...). A experiência e a observação aproximaram e confundiram essas duas ciências, por um longo tempo separadas por um falso espírito de sistema” (Guyton de Morveau, 1777, p. 336). Também o químico não era mais um ser de exceção, dotado de uma "paixão de louco", mas um cidadão integrado nas instituições do Estado ou empregado na incipiente indústria química. Essa mudança na apre- 
sentação da química e dos químicos feita por Guyton de Morveau exemplifica a passagem de uma imagem pública da química como ciência própria de uma cultura para outra que a via como uma atividade praticada por uma sociedade de profissionais (cf. Riskin, 2002, p. 235).

No artigo "Affinité", que também não existia na Enciclopédia, Guyton de Morveau (1776) recapitulava o ponto de vista que havia defendido na segunda parte de seu Digressões (1772) e retomava os principais argumentos apresentados por Macquer no artigo "Pesanteur" de seu Dicionário (cf. Macquer, 1766). Guyton de Morveau explicava as afinidades através da figura dos corpos em dissolução. Nessa operação, na qual as substâncias encontravam-se em uma relação exata de gravitação, Guyton de Morveau afirmava obedecer-se às duas condições necessárias para dissolver um corpo: a divisão e a equiponderância. A equiponderância correspondia a uma "exata relação de gravidade entre as partes do corpo dissolvido e aquele do fluído dissolvente", enquanto que a divisão era o produto de múltiplas atrações entre as partes integrantes e constituintes dos corpos. Da eliminação de parte da matéria que produzia a fluidez de uma dissolução obtinha-se uma cristalização. O conhecimento da forma geométrica dos cristais formados constituía uma plataforma de trabalho experimental na determinação das causas das diferentes afinidades entre as partes constituintes dos compostos (cf. Guyton de Morveau, 1776). Metzger identificou nessas considerações de Guyton de Morveau as origens da cristalografia desenvolvida posteriormente por René Just Haüy (cf. Metzger, 1969 [1921], p. 171).

Enfim, duas das principais características da identidade química defendida por Venel eram abolidas. Primeiro, os químicos não eram diferentes dos físicos no uso de teorias e instrumentos científicos. Segundo, o termo "mixto" deixava de nomear um território específico à química. Todavia, este abandono em favor de uma linguagem newtoniana para expressar as relações químicas não significava uma perda de identidade epistêmica por parte da química. A diferença entre a física e a química estava agora na escolha do raio de ação da força a ser estudada. A particularidade da química era, justamente, a de estudar essa força em distâncias infinitamente pequenas, onde as figuras ganhavam relevância. Como cabia à química investigar as propriedades dos corpos a partir de suas composições e recomposições, o conceito de "afinidade química" tornava-se central na identificação epistêmica dessa ciência e não mais o conceito de "mixto" (cf. Mocellin, 2011).

O desconhecimento da empreitada enciclopédica de Guyton de Morveau certamente empobrece a compreensão do historiador da química acerca da construção dos fatos científicos que provocaram a emergência do novo sistema lavoisieriano, bem como das razões de seus opositores. Mas, tão importante quanto conhecer o contexto dessa 
emergência, é a compreensão de um programa de investigação que pautava seus interesses em objetivos bem mais amplos do que aquele pretendido por Lavoisier. Dito de outro modo, o entendimento da química apresentada por Guyton de Morveau permite-nos compreender o lugar do tradicional programa dos sais da química francesa na formação de uma escola nacional. De fato, Guyton de Morveau foi um dos principais responsáveis por essa continuidade que, sob sua influência, consagrou esforços no sentido de aplicar um rígido método newtoniano na explicação e medida das afinidades químicas. Esse sólido programa newtoniano para a química teve uma profunda influência na formação do coletivo revolucionário francês (cf. Kim, 2003).

Por fim, cabe assinalar aqui o caráter comunitário que Guyton de Morveau imprimiu em seu trabalho enciclopédico. Ele expressou claramente essa direção a seu amigo Bergman, a quem demandava colaboração (cf. Guyton de Morveau, 1965 [178o]). Além de Bergman, Guyton de Morveau também mantinha uma intensa troca epistolar com os principais químicos europeus, como Kirwan, Lorenz von Crell, Felice Fontana, Marsilio Landriani, Claude-Louis Berthollet e Lavoisier, de modo que articulava uma rede de relações que permitia um debate contínuo entre centros importantes de produção do conhecimento químico das Luzes, como Uppsala, Londres e Paris.

\section{A revolução Linguística}

O interesse de Guyton de Morveau pela linguagem química começou durante a redação dos artigos para os Suplementos (1773-74) (cf. Smeaton, 1954). A confusão reinante na nomeação das substâncias químicas representava uma grande dificuldade não apenas na comunicação entre os químicos, mas também no ensino e na divulgação de sua ciência (cf. Crosland, $197^{8}$ [1962]). Pela primeira vez em sua história, a química terá uma dissertação acadêmica tratando exclusivamente de sua linguagem (cf. Guyton de Morveau, 1782).

Tendo por filosofia que os nomes eram convenções estabelecidas entre os falantes de uma língua e que a linguagem da química deveria ser objeto de consenso entre os membros da república dos químicos, Guyton de Morveau propôs um projeto de reforma em que solicitava as críticas e observações de seus pares. Seu projeto repousava em cinco princípios: (1) uma frase não é um nome; (2) as denominações devem ser convencionais e específicas; (3) é preferível um nome sem significado que uma denominação ligada a ideias falsas; (4) na introdução de um novo nome, este deve ter sua raiz em uma língua morta (latim, grego); (5) as denominações devem seguir as regras das línguas nacionais. 
Esses princípios, associados à regra binomial de Lineu, permitiram a Guyton de Morveau nomear e organizar em uma tabela os 18 ácidos e as 24 "bases" então conhecidas (4 terras, 15 metais, 3 álcalis, flogístico e álcool), bem como prever o nome de suas combinações, o que elevava para 500 substâncias cujas denominações poderiam ser facilmente conhecidas.

Os grandes representantes da república, como Macquer, Bergman, Buffon, Fontana, Kirwan, Crell, Lavoisier, dentre outros, acolheram com entusiasmo as propostas linguísticas de Guyton de Morveau. Esse método de nomenclatura passou a ser empregado nas traduções para o francês e os artigos publicados em jornais científicos, como o Observations sur la Physique e o Journal de Sçavans, também começaram a padronizar uma linguagem química. Ele também contribuiu na organização da linguagem química germânica, pois Crell, editor do principal jornal dedicado à ciência química em alemão (Chemische Annalen), passou a adotar seu método (cf. Mocellin, 2010, p. 252).

No prefácio da Enciclopédia metódica, Guyton de Morveau alerta os leitores que tratará da nomenclatura química no artigo "Dénomination”, mas como esse artigo não fazia parte do primeiro volume, ele esclarece que usará os mesmos princípios anunciados em 1782, agora corrigidos e aprovados pela república (cf. Guyton de Morveau, Maret \& Duhamel, 1786/1789, p. v-vi). O artigo aparecerá somente no quarto tomo, quando a Enciclopédia metódica estava sob responsabilidade de Antoine de Fourcroy, que reenvia o leitor às origens do projeto de Guyton de Morveau e ao segundo volume no qual este apresentava os princípios da nova nomenclatura química acordada pelo grupo reunido em Paris em 1787 (Fourcroy, 1805, p. 14,0). Mas, antes de tratarmos da formação desse grupo, cabe retraçar alguns aspectos importantes sobre as bases de negociação sobre as quais será formada a chamada "escola francesa de química".

No primeiro volume da Enciclopédia metódica, dois artigos se destacam. Um sobre os ácidos e outro sobre as afinidades químicas. O primeiro é um detalhado tratado com 4,36 páginas em duas colunas in quarto e o segundo, com $7^{8}$ páginas, a melhor exposição da época sobre o assunto. O artigo "Affinité” foi também publicado em separado e traduzido para o alemão, o italiano e o português. Nele, Guyton de Morveau reafirmava suas bases teóricas e descrevia outros métodos para medir as afinidades, além daquele que ele próprio havia desenvolvido. Segundo ele, os dados obtidos pelo químico alemão Franz Karl Achard lhe permitiam escrever uma formulação matemática para a adesão e, seguindo seu método de associação entre afinidade e adesão, uma possível expressão algébrica para as afinidades químicas (cf. Guyton de Morveau, Maret \& Duhamel, 1786/1789).

Era de se esperar que a redação do artigo sobre os ácidos trouxesse grandes dificuldades para alguém que "ainda” acreditava na existência do flogístico, uma vez que as experiências realizadas por Lavoisier desde 1777 mostravam que os ácidos resulta- 
vam da absorção de uma parte específica de ar presente no ar comum. Além disso, essa porção de ar absorvida, tanto na combustão quanto na calcinação, era a causa do aumento da massa do produto resultante. Na lógica da conversão paradigmática, seria impossível aceitar a teoria dos ácidos de Lavoisier (indissociável de sua teoria sobre a combustão e a calcinação) e também acreditar no fantasma do flogístico. Porém, a história mostra que, ao menos no caso de Guyton de Morveau, a relação com o sistema químico de Lavoisier e a futura aceitação de partes deste sistema não se dará na forma de uma conversão, de uma espécie de ascese místico-religiosa ou de mudança de gestalt.

Inicialmente, é necessário lembrar que a química para Guyton de Morveau era a ciência das dissoluções. O fogo era o responsável por todas as dissoluções. A parte do fogo retida durante a cristalização era o que Guyton de Morveau chamava de flogístico. Em uma primeira explicação sobre o aumento da massa do material calcinado, Guyton de Morveau considerou que o flogístico seria menos denso que todos os corpos químicos e que, por isso, quando combinado tornava seus compostos "mais leve". Assim, o metal seria mais leve que sua cal por estar combinado com uma porção de flogístico. Mas, ele estava a par das experiências de Lavoisier, tanto que viajou a Paris em 1775 e voltou a Dijon somente depois de estar convencido do rigor dos resultados que demonstravam que o ar absorvido era a única causa material desse aumento (cf. Smeaton, 1964, p. $5^{32}$ ).

Para dar conta dessa composição não esperada, Guyton de Morveau sugeria que no momento em que "uma parte do ar" era absorvida, o flogístico retido era liberado na forma de calor ou de luz. No artigo sobre as afinidades, ele lembra que na Academia de Dijon, desde a publicação das dissertações de Lavoisier sobre a combustão do fósforo e do enxofre, em 1777, ensinava-se que essa "parte do ar" absorvida, denominada de "ar vital", seria também a causa da acidificação. Ou seja, Guyton de Morveau admitia a existência de um princípio oxigênio, ou o princípio universal de acidez defendido por Lavoisier. Assim como o flogístico, o princípio acidificante e os novos ares que estavam sendo descobertos eram integrados por Guyton de Morveau no quadro teórico da química das dissoluções e no jogo das afinidades. Desse modo, quando escreveu o artigo sobre os ácidos, as opiniões de Guyton Morveau e de Lavoisier eram bastante convergentes (cf. Guyton de Morveau, Maret \& Duhamel, 1786/1789, p. 29).

Porém, uma vez demonstrado o aumento da massa e a absorção de "ar vital", por que Guyton de Morveau não abandonava a hipótese do flogístico? Simplesmente, porque as razões experimentais para abandonar o "fogo fixado" na explicação de alguns fenômenos eram inexistentes. Por exemplo, como explicar a origem do "ar inflamável" liberado quando um metal era dissolvido por um ácido? Até a decomposição da água, em 1785, Lavoisier não tinha nenhuma resposta convincente para essa questão. Ao contrário, esse "ar inflamável” foi considerado por muitos químicos o próprio 
flogístico em sua forma mais pura. Esse foi o caso de Kirwan, que propôs, em 1782, uma sólida teoria sobre as afinidades envolvendo o flogístico ou "ar inflamável" (cf. Mauskopf, 2002; Taylor, 2008).

Assim, longe de ser um programa moribundo, as investigações sobre o flogístico ganharam destaque nos anos 1780. Em relação à água, Guyton de Morveau estava de acordo com Lavoisier de que ela não era um corpo simples. A diferença entre suas interpretações consiste em que, para Lavoisier, a água era uma combinação entre o "ar vital" e o "ar inflamável”, enquanto que para Guyton de Morveau ela era formada pelo "princípio oxigênio" unido ao calórico.

De fato, a julgar por uma tabela preparada em 1786 e fixada no laboratório da Academia de Dijon, as divergências entre Guyton de Morveau e Lavoisier eram poucas no momento da publicação do primeiro volume da Enciclopédia metódica, embora importantes. Nela podemos identificar que eles estavam de acordo sobre a composição do calórico, do ar vital, das cales metálicas, sobre a presença do princípio oxigênio nos ácidos e sobre a decomposição da água (cf. Guyton de Morveau, ${ }_{17} 87$ ). O "ar inflamável” originava-se certamente da água (era a explicação de Lavoisier), de modo que os metais não eram substâncias compostas de uma base combinada com certa quantidade de flogístico; porém, como explicar a diferença de comportamento da combustão do enxofre e do fósforo, senão pela maior ou menor afinidade destes como o flogístico? Enquanto Lavoisier considerava que essas combinações ocorriam por afinidade de composição (simples) $(\mathrm{A}+\mathrm{BC} \rightarrow \mathrm{AB}+\mathrm{C})$, Guyton de Morveau pensava que elas ocorriam através de uma afinidade dupla $(\mathrm{AB}+\mathrm{CD} \rightarrow \mathrm{AD}+\mathrm{CB})$. Quer dizer, a discussão acontecia no âmbito da teoria das afinidades e não da defesa de uma "tradição de pensamento" acerca de um suposto princípio de inflamabilidade ou de metalicidade.

Publicado o primeiro volume da Enciclopédia metódica, Guyton de Morveau começou a redigir o próximo artigo, no qual aborda diretamente a teoria química da combustão e da calcinação. Trata-se do artigo "Air", que somente será publicado em 1789 (cf. Guyton de Morveau, Maret \& Duhamel, 1786/1789, p. 665-771). A fim de sanar suas dúvidas quanto aos resultados experimentais obtidos por Lavoisier no laboratório do Arsenal, Guyton de Morveau viajou a Paris em 1787. Em sua estada parisiense, que se estendeu de fevereiro a agosto, Guyton de Morveau foi acolhido pelo grupo formado em torno de Lavoisier, que contava com químicos já consagrados como Berthollet e Fourcroy, mas também com jovens promissores como Pierre Auguste Adet e JeanHenri Hassenfratz.

Em geral, os historiadores da química interpretaram esse período como o momento em que Guyton de Morveau se converteu ao sistema químico de Lavoisier, abjurando o flogístico e abraçando a nova química (cf. Bensaude-Vincent, 1993, p. 264). 
De nossa parte, consideramos que essa noção de "conversão" dificulta a compreensão do papel de Guyton de Morveau e do programa de investigação que ele representa na química francesa do final do século xviıI. Não nos parece que um encontro sobre problemas técnicos e teóricos específicos tenha causado em Guyton de Morveau efeito semelhante ao da experiência de um Paulo de Tarso em viagem a Damasco. A química que ele ensinará após sua ligação com os químicos de Paris não será muito diferente daquela que ensinou durante seus longos anos na Academia de Dijon.

Deixando de lado essa noção, é mais interessante dar atenção às razões que levavam Guyton de Morveau a considerar que o flogístico ainda era uma realidade experimental. Dois problemas o intrigavam. Um era sobre a composição da água, outro era sobre a combustão do carbono, do fósforo e do enxofre. A respeito do caráter composto da água, Guyton de Morveau tinha dúvidas se, de fato, ela era formada pela combinação de "ar vital" e de "ar inflamável". Seu amigo Kirwan chamava sua atenção para o fato de que se ele admitisse a decomposição da água, não haveria mais muitos obstáculos para descartar o flogístico (cf. Kirwan, 1994 [1787]). Mas restava o problema das combustões, pois enquanto o fósforo queimava espontaneamente, o enxofre e o carvão precisavam de uma ignição inicial.

A composição da água foi o primeiro ponto de acordo entre Guyton de Morveau e o grupo de Lavoisier. Kirwan tinha razão em apontar que aceitar a decomposição da água implicava descartar a presença de flogístico nos metais. Ou seja, Guyton de Morveau estava de acordo não apenas com o caráter composto da água, mas também de que os metais não eram compostos e sim corpos simples. Quanto ao tipo de afinidade envolvido na combustão, uma pista para compreendermos o que levou Guyton de Morveau a aceitar que ela não era dupla e sim simples são as notas feitas pelo grupo para a tradução da obra Ensaio sobre o flogístico (An essay on phlogiston) de Kirwan, por Marie-Anne Paulze, esposa de Lavoisier (cf. Kirwan, 1788).

A explicação dada por Lavoisier ao calórico, em seu comentário sobre a introdução de Kirwan, indica-nos que a maioria das propriedades atribuídas ao princípio do calor correspondia àquelas que Guyton de Morveau nomeava como flogístico. É muito provável que Lavoisier tenha convencido Guyton de Morveau de que era possível manter sua concepção de química como "ciência das dissoluções", mudando o nome do dissolvente universal. Esse dissolvente não era mais o flogístico, mas sim o calórico. Certamente, atribuir a propriedade dissolvente ao calórico não significava que ele pudesse assumir todas as funções do flogístico. Transferido ao calórico as propriedades ligadas ao fogo, restava saber o tipo de afinidade entre os combustíveis e o princípio oxigênio. A constatação de que a combinação da base do "ar vital" com os corpos combustíveis era direta, e de que a diferença nos padrões de combustão era devida à tem- 
peratura em que era realizada, fez com que Guyton de Morveau abandonasse definitivamente o flogístico como parte constituinte dos corpos combustíveis e transferisse todas as propriedades do fogo enquanto princípio combinado ao calórico.

O importante a destacar nesse abandono não é uma suposta conversão paradigmática, mas a sua concordância com a teoria de Lavoisier sobre a composição, considerada por alguns o núcleo duro da revolução lavoisieriana (cf. Siegfried \& Dobbs, 1968). Todavia, essa teoria somente foi admitida depois de ter sido assimilada à teoria das afinidades químicas. Aqui temos uma diferença considerável entre os objetivos de Lavoisier e de Guyton de Morveau no plano teórico. Se no sistema de Lavoisier o essencial era demonstrar as consequências de uma "química do oxigênio", para Guyton de Morveau o importante era integrar esse princípio ao quadro das afinidades. Esta diferença ganha contornos precisos ao avaliarmos os propósitos de Lavoisier e de Guyton de Morveau em seus textos posteriores. Enquanto o Tratado elementar de química (1937 [1789]) de Lavoisier é uma obra centrada no conceito de análise química e de corpo simples, deixando de lado o complexo assunto das afinidades, os artigos de Guyton de Morveau para o segundo volume da Enciclopédia metódica tratarão das composições partindo, justamente, desse quadro conceitual.

Embora haja certo consenso da parte dos historiadores em considerar esse ato de conversão como um evento histórico, o papel de Guyton de Morveau no projeto de reforma da nomenclatura química gera divergências. Por exemplo, enquanto Maurice Crosland (1978 [1962]), William Smeaton (1954), Frederic Holmes (1995) e BensaudeVincent (1993) consideram que a reforma de 1787 era uma continuidade do projeto iniciado em 1782, Marco Beretta (1993) pensa que o método linguístico de Lavoisier marca uma ruptura radical com aquela tradição de reforma.

Deixar de lado a imagem de que o encontro com Lavoisier representou a conversão de Guyton de Morveau, ajuda-nos a melhor compreender os interesses de cada um nesse projeto de reforma da linguagem. Estamos de acordo com aqueles historiadores que veem uma continuidade entre os programas de $17^{82}$ e 1787 , todavia, parece-nos haver uma profunda diferença entre as intenções de Lavoisier e as de Guyton de Morveau. Seguindo os objetivos traçados em 1782, Guyton de Morveau trabalhava em uma nomenclatura por consenso, que não fosse específica a uma teoria, enquanto Lavoisier considerava que a nomenclatura era o reflexo de uma teoria química verdadeira, a sua.

Esse trabalho de nomenclatura química foi apresentado no final daquele ano à Academia de Ciências de Paris (cf. Guyton de Morveau et al., 1994. [1787]). De fato, existe uma profunda clivagem filosófica entre os projetos linguísticos de Lavoisier e de Guyton de Morveau. A primeira dissertação, escrita por Lavoisier, defendia a necessidade de modificar a linguagem química e que, para isso, devia-se adotar o princípio 
condillaquiano, segundo o qual toda língua era um "método analítico". Linguagem e conhecimento seriam indissociáveis. A partir dessa filosofia da linguagem, Lavoisier tentava atrelar a nomenclatura química a sua teoria química centrada no oxigênio. Assim, os químicos que adotassem os novos nomes ver-se-iam obrigados a reconhecer como verdadeira a teoria lavoisieriana da composição e da acidez. Talvez tenha sido esta consequência lógica que afastou, ou pelo menos diminuiu consideravelmente a participação de Berthollet no projeto de reforma. Berthollet tinha sérias dúvidas quanto à universalidade atribuída ao oxigênio como princípio de acidez e limitou-se a emprestar seu nome para que a empresa tivesse um caráter de consenso entre os principais químicos nacionais (cf. Le Grand, 1975).

Guyton de Morveau discordava dessa "metafísica de línguas" adotada por Lavoisier. Encarregado de apresentar os aspectos técnicos na segunda dissertação da obra, ele procurou separar a nova nomenclatura de uma teoria química particular. Seguindo Locke, Guyton de Morveau pensava as palavras como convencionais, e que o seu significado resultava mais de um acordo coletivo que de uma essência qualquer. $\mathrm{Na}$ teoria condillaquiana da linguagem, a relação significado/significante também era convencional, porém, diferentemente de Locke, a linguagem era o método analítico que produzia todo nosso conhecimento. Enfim, se Lavoisier reivindicava Condillac na adoção de seu "método de nomear", Guyton de Morveau não abandonava o convencionalismo empirista lockeano que adotou na reforma de 1782 (cf. Simon, 2002).

O problema em adotar uma linguagem que espelhasse o encadeamento das ideias químicas segundo uma teoria particular era o de não alcançar o consenso da república que toda linguagem deveria ter. Diferentemente de Lavoisier, que publica um livro para defender a sua teoria, Guyton de Morveau continua seu trabalho de professor e de enciclopedista, e nessas atividades a defesa de um único ponto de vista era interditada. Assim, as diferenças teóricas e linguísticas entre Lavoisier e Guyton de Morveau podem ser percebidas em suas atividades após 1787 .

Os defensores de uma conversão teórica radical certamente relativizariam suas posições se tivessem tido acesso aos cursos dados por Guyton de Morveau após sua estada em Paris. Recentemente, os historiadores passaram a dispor de um manuscrito do curso da Academia de Dijon ministrado por Guyton de Morveau em 1789. O texto de Claude Antoine, compte Prieur-Duvenois, não deixa dúvidas de que a teoria química ensinada por Guyton de Morveau continuava centrada no conceito de dissolução (agora provocada pelo calórico) e de afinidades químicas. A nova "química do oxigênio" era um capítulo a mais na exposição (cf. Mocellin, 2010).

Pode-se contestar essa interpretação evocando a Advertência escrita por Guyton de Morveau (1789) para o segundo volume da Enciclopédia metódica. Segundo BensaudeVincent, nesse texto, Guyton de Morveau teria começado a estabelecer as bases do mito 
Lavoisier, pois o saudava como um herói na busca da verdade, um novo Descartes que viera impor um método seguro na condução do conhecimento químico (cf. BensaudeVincent, 1993, p. 263). Todavia, não nos parece ser esse o caso. Primeiramente, a advertência de Guyton de Morveau é relativa unicamente ao abandono do flogístico e não acerca de uma revolução que teria abalado a química como um todo. Se Guyton de Morveau saúda a semelhança do "espírito filosófico" de Lavoisier com o de Descartes, é para observar que quando Lavoisier decidiu descartar o flogístico, ele seguia mais uma crença teórica do que as evidências empíricas disponíveis. Dito de outro modo, Guyton de Morveau compara Lavoisier a Descartes apenas para mostrar que, às vezes, a crença em uma teoria racional contrária aos dados da experiência pode render bons frutos.

Uma abordagem da reforma da nomenclatura levando em consideração apenas o programa teórico de Lavoisier, além de ocultar outras ramificações epistêmicas, também deixa de lado um aspecto importante na difusão da nova linguagem. Para o grande público, ao menos na França, as transformações científicas eram percebidas e assimiladas na medida em que entravam em um discurso didático, de formação e de divulgação. Os dois projetos enciclopédicos atestam esse processo de assimilação das transformações revolucionárias ocorridas na química na segunda metade do século. Será através de Guyton de Morveau que a nova nomenclatura ganhará a publicidade e o caráter de universalidade sugerido pelo discurso enciclopédico.

A difusão da nova nomenclatura química para além das fronteiras francesas demonstra que os químicos estrangeiros tenderam a adotar essa nomenclatura, mas não os fundamentos filosóficos defendidos por Lavoisier (cf. Bensaude-Vincent \& Abbri, 1995). Parece-nos, assim, que o sucesso da nova nomenclatura química deveu-se, sem dúvida, por ela fundar-se em uma convincente teoria da composição química, mas somente conquistou a república dos químicos graças à técnica binomial, ao convencionalismo linguístico e ao espírito enciclopédico de Guyton de Morveau.

\section{Conclusão}

No rio Diderot, os comentadores demonstraram que a turbulência de suas águas era causada por forças mais profundas que emergiam do leito perene de seu naturalismo e de seu materialismo (cf. Souza, 2002). Uma de suas fontes foi a Enciclopédia, que operava como uma verdadeira máquina de propaganda de uma filosofia sensualista e de uma nova visão acerca do valor social e cultural do conhecimento científico. Dela nasceu o conceito historiográfico que nos guiou na descrição da trajetória revolucionária de Guyton de Morveau em matéria de ensino, na descrição dos fundamentos teó- 
ricos da química das Luzes e na construção de uma linguagem que refinava a comunicação comunitária.

Se a metáfora fluvial sugere a imprecisão espaço-temporal do evento histórico e a pluralidade de interpretações histórico-epistemológicas, é inegável que um de seus mais poderosos afluentes conceituais foi a obra de Lavoisier e suas diferentes leituras. Mas o conhecimento químico do século xviıI não se restringia aos sugeridos por Lavoisier, simplesmente porque o sistema químico apresentado por ele limitava-se a um domínio particular da química praticada na época.

Apontamos que uma das razões para a centralidade de Lavoisier nas interpretações da revolução química foi a criação, não de uma química moderna, mas de um conceito historiográfico que teve profundas implicações nas interpretações epistemológicas do evento. Para evidenciarmos outros domínios teóricos e experimentais que ocupavam os químicos das Luzes, bem como o significado da noção de progresso científico ao longo do século, partimos de outra concepção historiográfica de revolução científica, aquela que operava e articulava a descrição dos conhecimentos técnicos, científicos e filosóficos no interior dos dois grandes projetos enciclopédicos empreendidos na França da segunda metade daquele século.

Essa reformulação conceitual da expressão "revolução química" não pretende nem contestar o caráter revolucionário de Lavoisier, nem sustentar que o significado enciclopédico que a ela atribuímos seja de aplicação geral para a compreensão das revoluções científicas que ocorreram no século xvııı.

Seu primeiro objetivo foi historiográfico, pois com isso podemos diferenciar dois conceitos que operaram na escrita de uma história da química, particularmente da química das Luzes. Evitando o telos da refundação que uma revolução lavoisieriana obriga, a revolução enciclopédica entendida como as transformações que uma ciência sofre no seio de uma comunidade de praticantes, ajuda-nos a compreender melhor as questões filosóficas e operacionais que ocupavam os químicos em seus diversos níveis de atividade (autor, professor, experimentador, divulgador, político ...). A partir dessa redefinição e delimitação histórica do conceito, procuramos evidenciar o significado de fazer-se uma revolução na química, abordando alguns temas chaves que caracterizavam essa ciência como um conhecimento autônomo.

Em segundo lugar, apontando as diferenças na apresentação da química ao grande público nas duas enciclopédias, acentuamos a concepção de Guyton de Morveau acerca do que seria próprio da química e do lugar social de seus praticantes. Seu caso é representativo no entendimento dos esforços dos químicos do século das Luzes na construção de uma identidade epistêmica e de um programa de desenvolvimento teórico-experimental a partir da generalização do conceito newtoniano de afinidade, ou de atração entre os corpos químicos. Isso fez com que destacássemos um dos campos de pesquisa 
mais vigorosos do século xvııI, que não foi o território favorito das investigações de Lavoisier na construção de seu sistema químico (cf. Lavoisier, 1937 [1789]).

Uma melhor contextualização histórica da revolução química, oferecida tanto pelas análises que limitam seu escopo a Lavoisier, quanto pelas que a tomam em sentido mais amplo, causa certa frustração naqueles que buscam uma explicação racional unificada, e certo pessimismo quanto aos resultados da relação entre a história e a filosofia da ciência. Por exemplo, em seus escritos pós-Estrutura, Kuhn insistiu na ideia de que a história e a filosofia da ciência eram disciplinas diferentes, com estatutos disciplinares e epistêmicos próprios e que, portanto, não deveriam ser praticadas conjuntamente (cf. Kuhn, 1989 [1977]). Seguindo uma tradição reforçada por Imre Lakatos e Alan Musgrave, outros comentadores não abandonaram a convicção de que existe uma permanente interdependência entre a história e a filosofia da ciência, e que os problemas dialógicos devem ser encarados como estímulo a novas pesquisas (cf. Chang, 2010).

Como neste artigo abordamos a ciência química e limitamo-nos a um momento particular de sua história, seria precipitado tecer considerações gerais sobre a interação história/filosofia da ciência. Certamente, categorias tradicionais da filosofia da ciência, tais como indução/dedução, realismo/convencionalismo ou ciência normal/ciência revolucionária, não são as mais indicadas na compreensão de questões próprias ao desenvolvimento da química. Partindo de um caso particular dessa ciência, podemos apontar que talvez o mais interessante não seja aplicar os conceitos filosóficos tradicionalmente desenvolvidos pelos epistemólogos na investigação histórico-filosófica da química, mas fazer emergir questões filosóficas que ocuparam os químicos e construíram canais de diálogo com filósofos e historiadores. Quer dizer, antes de perguntarmo-nos se a história da química comprova este ou aquele modelo epistemológico, parece-nos mais instrutivo procurarmos descrever as questões filosóficas que a química suscita ela mesma, em seus diversos níveis de atuação social.

\section{Ronei Clécio Moceluin}

Pós-doutorando do Departamento de Filosofia, Faculdade de Filosofia, Letras e Ciências Humanas, Projeto Temático Fapesp 2011/51614-3,

"Gênese e significado da tecnociência", Instituto de Estudos Avançados, Universidade de Sâo Paulo, Fundação de Amparo à Pesquisa do Estado de São Paulo, Brasil. r.cleciomocellin@gmail.com 


\begin{abstract}
The aim of this paper is to investigate the encyclopedic conception of scientific revolution implemented by the French chemist L-B. Guyton de Morveau (1 $\left.737^{-1816}\right)$. Shifting the analysis of chemical knowledge of the Enlightenment program outlined by Lavoisier (174.3-1794), we suggest a Republican revolutionary conception, brought about as a result of a collective effort. We will highlight three of Guyton de Morveau's revolutionary approaches to Chemistry. The first was his role in the teaching of this science, the pedagogy and teaching methods of which were fundamental for its becoming embedded socially. In addition, between $177^{\circ}$ and 1790, Guyton de Morveau played central roles in the encyclopedic enterprise and the French chemistry school.
\end{abstract}

KeYwords • Chemical revolution. Guyton de Morveau. Encyclopédie méthodique. Chemical affinities,

\title{
REFERÊNGIAS BIBLIOGRÁFIGAS
}

Actes de Colloques. Il y a 200 ans Lavoisier. Académie des Sciences de Paris (Org.). Paris: Éditions Tec \& Doc, 1995 .

Bachelard, G. Le pluralisme cohérent de la chimie moderne. Paris: Vrin, 1973 [1932].

BAUdot, A. La pharmacie en Bourgogne avant 1803. Mâcon: JPM, 2002 [1905].

Belmoste, B. Del'École des Pontes et Chausses à l'École Central des Travaux Publics. Nouveaux documents sur la fondation de l'École Polytechnique. SABIX, 11, p. 1-69. 1994. Disponível em: <http:// www.sabix.org/bulletin/sabixb11.htm>. Acesso em: 10 dez. 2012.

Bensaude-Vincent, B. Lavoisier: mémoire d'une révolution. Paris: Flammarion, 1993.

_. Matière à penser. Essais d'histoire et de philosophie de la chimie. Paris: Presses Universitaires de Paris Ouest, 2008.

. Le mixte, ou l'affirmation d'une identité de la chimie. Corpus, Revue de Philosophie, 56, p. 117-42, 2009 .

Bensaude-Vincent, B. \& AbBri, F. (Ed.). Lavoisier in European context: negotiating a new language for chemistry. Canton: Science History Publications, 1995.

Beretta, M. The enlightenment of matter: the definition of chemistry from Agricola to Lavoisier. Canton: Science History Publications, 1993.

Blanckaert, C. \& Porret, M. (Ed.). L'Encyclopédie méthodique (1782-1832): des lumières au positivisme. Genève: Droz, 2006.

Bots, H. \& Waquet, F. La république des lettres. Paris: Belin-De Boeck, 1997.

BREt, P. Les chimies de l'Encyclopédie méthodique: une discipline académique en révolution et des traditions d'atelier. In: Blanckaert, C. \& Porret, M. (Ed.). L'Encyclopédie méthodique (1782-1832): des lumières au positivisme. Genève: Droz, 2006. p. 521-51.

. Les promenades littéraires de madame Picardet. La traduction comme pratique social de la science au xvirIe siècle. In: Duris, P. (Ed.). Traduire la science, hier et aujourd'hui. Pessac: Maison des Sciences de l'Homme d'Aquitaine, 2008a. p. 125-52.

. "Ils ne forment tous qu'une même République". Académies, amateurs et savants étrangers dans la correspondance des chimistes à la fin du $18^{\mathrm{e}}$ siècle. Dix-huitième Siècle, 4.०, 2008b, p. 263-79.

CARLid, G. \& Nordström, J. Torbern Bergman's foreign correspondence. Stockholm: Almqvist \& Wiskel, 1965.

Chang, H. The hidden history of phlogiston: how philosophical failure can generate historiographical refinement. HYLE, 16, 2, p. 47-79, 2010. 
Chartier, R. L'éducation en France au xvième au xviiième siècle. Paris: Société d'Éditon d'Enseignement, 1976.

Cohen, I. B. Revolution in science. Cambridge: Harvard University Press, 2001 [1985].

Cohen, I. B. \& Taton, R. (Ed.). L'aventure de la science: mélanges Alexandre Koyré. Paris: Hermann, 1964.

Crosland, M. Historical studies in the language of chemistry. New York: Dover, 1978 [1962].

Dagognet, F. Tableaux et langages de la chimie: essai sur la représentation. Paris: Champ Vallon, 2002 [1969].

Darton, R. O iluminismo como negócio. São Paulo: Companhia das Letras, 1996.

Daumas, M. La chimie dans l'Encyclopédie et dans l'Encyclopédie méthodique. Revue d'Histoire des Sciences, 4, p. $134,4,3,1951$.

Delon, M. (Ed.). Dictionnaire européen des lumières. Paris: PUF, 1997.

Demeulenaere-Douyère, C. \& Brian, E. (Org.). Règlement, usages et science dans la France de l'absolutisme. Paris: Éditions Tec \& Doc, 1999.

Diderot, D. \& D’Alembert J.R. (Ed.). Encyclopédie, ou Dictionnaire raisonné des sciences, des arts et des métier. Stuttgart-Bad Cannstatt: Verlag, 1967 [1751- 72$]$ (Nouvelle impression en facsimilé de la première édition).

Donovan, A. Antoine Lavoisier: science, administration and revolution. Oxford : Blackwell, 1993.

Fontenay, E. Diderot ou le matérialisme enchanté. Paris: Grasset, 1982.

Fourcroy, A. (Ed.). Encyclopédie méthodique. Chymie et métallurgie. Paris: H. Agasse, t. 4, 1805 (Ano 13).

GUERLAC, H. The crucial year: the background and origin of his first experiments on combustion in 1772. Ithaca: Cornell University Press, 1961.

GuYton de Morveau, L. B. Mémoire sur l'éducation publique. Dijon: [s.n.], 1764.

Digressions académique, ou essai sur quelques sujets de physique, de chymie \& d'histoire naturelle. Dijon: Frantin, 1772.

. Affinité. In: Panckougke, C.L. \& Robinet, J.B.R. (Ed.). Suppléments à l'Encyclopédie. Amsterdam: Rey Libraire, 1776 . v. 1. p. 182-4.

. Phlogistique. In: Panckoucke, C.L. \& Robinet, J.B.R. (Ed.). Suppléments à l'Encyclopédie. Amsterdam: Rey Libraire, 1777. v. 4. p. 336-40.

. Éléments de chymie, théorique et pratique. Dijon: Frantin, $1777^{/} 7^{8}$. 3 v.

. Mémoire sur les dénominations chimiques, la nécessité d'en perfectionner le système, les règles pour y parvenir, suivi d'un tableau d'une nomenclature chimique. Observations sur la Physique, 19, p. $370-82,1782$.

. Sur une table synoptique des parties constituantes de quelques substances principales, suivant toutes les hypothèses. Observations sur la Physique, 3o, p. 45-4,6, 1787 .

. Lettre de Guyton de Morveau à Bergman du 22 novembre 1780. In: CArLid, G. \& Nordström, J.

(Ed.). Torbern Bergman's foreign correspondence. Stockolm: Almqvist \& Wiskel, 1965 [1780]. p. 112.

. Dénominations. In: Fourcroy, A. (Ed.). Encyclopédie méthodique. Paris: Agasse, v. 4, 1805 (Ano 13). p. 140.

Guyton de Morveau, L. B.; Lavoisier, A. L.; Berthollet, C. L.; Fourcroy, A.F.; Hassenfratz, J.H. \& Adet, P.A. Methode de nomenclature chimique. Paris: Édition de Seuil, 1994 [1787].

Guyton de Morveau, L.B.; Maret, H. \& Duhamel du Mongeau, H.-L. (Ed.). Encyclopédie méthodique. Chymie, pharmacie et métallurgie. Paris: Panckoucke; Liège: Plomteaux, t. 1. Duas partes: 1786/1789.

HannaWaY, O. The chemists \& the word: the didactic origins of chemistry. Baltimore: Johns Hopkins University Press, 1975 .

Holmes, F. L. Analysis by fire and solvent extractions: the metamorphosis of a tradition. Isis, 62, p. 129$48,1971$.

. Eighteenth-century chemistry as on investigative enterprise. Berkeley: University of California Press, 1989 . 
Louis-Bernard Guyton de Morveau e a revolução química das Luzes

Beyond the boundaries. In: Bensaude-Vingent, B. \& Abbri, F. (Ed.). Lavoisier in European context: negotiating a new language for chemistry. Canton: Science History Publications, 1995 · p. 267-78.

Hoyningen-Huene, P. Thomas Kuhn and the chemical revolution. Foundations of Chemistry, 10, 2, p. $101-$ $15,2008$.

Kıм, M. G. Affinity, that elusive dream: a genealogy of the chemical revolution. Cambridge: MIT Press, 2003.

Kinwan, R. Essai sur le phlogistique et sur la constitution des acides. Tradução M.-A. P. Lavoisier. Paris: Rue et Hôtel Serpente, 1788 .

Lettre du 2 avril 1787 à Guyton de Morveau. In: Grison, E.; Goupil, M. \& Bret, P. (Ed.). A scientific correspondence during the chemical revolution. Berkeley: University of California Press, 1994 [1787]. p. $165^{-7}$.

KLEIN, U. \& LefÈVRE, W. Materials in eighteenth-century science: a historical ontology. Massachusetts: MIT Press, 2007.

Kunn, T. S. A estrutura das revoluções científicas. São Paulo: Perspectiva, 1975 [1962]. As relações entre a história e a filosofia da ciência. In: A tensão essencial. Lisboa: Edições 7̧, 1989 [1977]. p. 29-49.

LAGRÉE, Y. La Chalotais (1701-1785). Un magistrat pédagogue au siècle des Lumières. In: Éducation et pédagogies au siècle des Lumières. Actes du colloque 1983 de l'Institut des sciences de l'éducation. Angers: Université Catholique de l'Ouest, 1985. p. 189-203.

Lamarre, G. L'organisation de la discussion scientifique autour de Guyton de Morveau et de Maret: l'Académie de Dijon entre 1780 et 1788. In: Demeulenaere-Douyère, G. \& Brian, E. (Org.). Règlement, usages et science dans la France de l'absolutisme. Paris: Éditions Tec \& Doc, 1999. p. 293-305.

Lavoisier, A. Opuscules physiques et chymiques. Paris: Deterville, 1801 [1774]. . Traité élémentaire de chimie. Paris: Guther-Villar Éditeur, 1937 [1789].

Le Grand, H. E. The “conversion” of C.-L. Berthollet to Lavoisier' chemistry. Ambix, 22, p. 88-105, 1975.

Lehman, C. Gabriel-François Venel (1723-1775): sa place dans la chimie française du xviiie siècle. Lille: Atelier National de Reproduction des Thèses, 2008.

Lehman, C. \& Pépin, F. La chimie et l'Encyclopédie: introduction. Corpus, Revue de Philosophie, 56, p. 5-36, 2009.

Macquer, P.J. Dictionnaire de chymie. 1. ed. Paris: Lacombe, 1766,2 v.

Mauskopf, S. Richard Kirwan's phlogiston theory: its success and fate. Ambix, 49, p. 185-205, 2002.

McEvoy, J. The historiography of the chemical revolution: patterns of interpretation in the history of science. London: Pickering \& Chatto, 2010.

Metzger, H. Introduction à l'étude du rôle de Lavoisier dans l'histoire de la chimie.Archeion, 14, p. 3152,1932 .

. La genèse de la science des cristaux. Paris: Albert Blanchard, 1969 [1921].

Newton, Stahl, Boerhaave et la doctrine chimique. Paris: Albert Blanchard, 1974, [1930].

Mocellin, R. G. Louis-Bernard Guyton de Morveau: chimiste et professeur au siècle des lumières. Saarbrücken: Éditions Universitaires Européennes, 2010.

"O sonho newtoniano" de Guyton de Morveau. Circumscribere, 10, p. 22-39, 2011.

Panckougke, G.L. \& Robinet, J.B.R. (Ed.). Suppléments à l’Encyclopédie. Amsterdam: Rey Libraire, 1776/ $77 \cdot 4 \mathrm{v}$.

PÉPIn, F. Diderot: La chimie comme modèle d'une philosophie expérimentale. Dix-huitième Siècle, 42, p.445-72, 2010.

QuARFood, C. Condillac, la statue et l'enfant: philosophie et pédagogie au siècle des lumières. Paris: L'Harmattan, 2002.

Reichardt, R. Révolution. In: Delon, M. (Ed.). Dictionnaire européen des lumières. Paris: PUF, 2007. p. $1079^{-84}$. 
RIskin, J. Science in the age of sensibility: the sentimental empiricist of the French enlightenment. Chicago: University of Chicago Press, 2002.

Rorgue, F. Guyton de Morveau en Bourgogne: itinéraire d'un dijonais au xviiième siècle et sous la révolution. Mémoire de Master II, Université de Dijon, 2006.

Siegfried, R. \& Dobbs, B. Composition, a neglected aspect of the chemical revolution. Annals of Science, 24,4, p. $275-93,1968$.

Simon, J. L'homme de verre? Les trois règnes et la promiscuité de la nature. Corpus, Revue de Philosophie, 36, p. $65^{-80}, 1999$.

Authority and authorship in the method of chemical nomenclature. Ambix, 49, 3, p. 206-226, 2002.

Smeaton, W. The contribution of P. J. Macquer, T. O. Bergman and L. B. Guyton de Morveau. Annals of Science, 10, p. 87-106, 1954 .

. Guyton de Morveau and the phlogiston theory. In: Cohen, I. B. \& Taton, R. (Ed.). L'aventure de la science: mélanges Alexandre Koyré. Paris: Hermann, 1964. p. 522-4,0.

Souza, M. G. de. Natureza e ilustração: sobre o materialismo de Diderot. São Paulo: Editora UNESP, 2002.

TAYLoR, G. Tracing influence in small steps: Richard Kirwan's quantified affinity theory. Ambix, 55, 3, p. 209-31, 2008.

Thagard, P. A estrutura conceitual da revolução química. Trad. M. R. da Silva \& M. Giro. Princípios, 14, 22, p. 265-303, 2007 [1990].

Tucco-Chala, S. Charles-Joseph Panckoucke \& la librairie française. Pau: Éditions Marrimpouy Jeune, 1977.

Venel, G. F. Chymie. In: Diderot, D. \& D’Alembert J.R. (Ed.). Encyclopédie, ou Dictionnaire raisonné des sciences, des arts et des métier. Stuttgart-Bad Cannstatt: Verlag, v. 3, ${ }_{1967}$ [1753]. p. 4.08a-437b.

Feu. In: Diderot, D. \& D’Alembert J.R. (Ed.). Encyclopédie, ou Dictionnaire raisonnédes sciences, des arts et des métier. Stuttgart-Bad Cannstatt: Verlag, v. 6, 1967 [1756]. p. 6o9-12.

. Mixte \& Mixtion. In: Diderot, D. \& D’Alembert J.R. (Ed.). Encyclopédie, ou Dictionnaire raisonné des sciences, des arts et des métier. Stuttgart-Bad Cannstatt: Verlag, Encyclopédie, v. 10, 1967 [1765]. p. $5^{8} 5^{b-} 5^{88 a}$. 